Journal of Thermal Engineering, Vol. 7, No. 3, pp. 468-482, March, 2021

Yildiz Technical University Press, Istanbul, Turkey

\title{
THERMAL DESIGN, ANALYSIS AND TEST VALIDATION OF TURKSAT-3USAT SATELLITE
}

\author{
Murat Bulut ${ }^{1, *}$, Nedim Sözbir ${ }^{2}$
}

\begin{abstract}
When CubeSat projects are a useful means by which universities can engage their students in space-related activities. TURKSAT-3USAT is a three-unit amateur radio CubeSat jointly developed by the Space Systems Design and Test Laboratory and the Radio Frequency Electronics Laboratory of Istanbul Technical University (ITU), in collaboration with TURKSAT, A.S. company as well as the Turkish Amateur Technology Organization. It was launched on April 26, 2013 as a secondary payload on a CZ-2D rocket from China's Jiuquan Space Center to an altitude of approximately $680 \mathrm{~km}$. The mission of the satellite has two primary goals: (1) to voice communication at Low Earth Orbit (LEO) and (2) to educate students by providing hands-on experience. TURKSAT-3USAT was designed to sustain a circular, near sun-synchronous LEO, and has dimensions of $10 \times 10 \times 34 \mathrm{~cm}^{3}$. Within the course of this paper, TURKSAT-3USAT's thermal control will be addressed. TURKSAT-3USAT's thermal control model was developed using ThermXL and ESATAN-TMS software. Using this model, temperature distributions of the CubeSat when subjected to various experimental conditions of interest were computed. Using a thermal vacuum chamber (TVAC), thermal cycling and bake-out testing were carried out on the flight model to verify the thermal design performance and check the mathematical model. Based on thermal analysis results, the temperature of equipment was within the allowable temperature range except for the batteries that were between $42.56^{\circ} \mathrm{C}$ and $-20.31{ }^{\circ} \mathrm{C}$. Heaters were used for the batteries in order to maintain the batteries' temperature within the allowable temperature range.
\end{abstract}

Keywords: $3 U$ CubeSat, Low Earth Orbit, Thermal Design, Thermal Analysis, Thermal Test

\section{INTRODUCTION}

Recently, the space industry has sought to leverage advances in technology miniaturization which can allow the construction of small-scale spacecrafts from commonplace, inexpensive, low-power and compact commercial offthe-shelf (COTS) components [1]. This trend has inspired the rise in popularity of CubeSat projects [2]. CubeSat missions typically serve to further student education, technological demonstration or some kind of scientific pursuit such as imaging or communications and tend to feature launch masses in the range of 1 to $10 \mathrm{~kg}$ [3]. CubeSat projects were first conceived of in 1999 by Dr. Jordi Puig-Suari of the California Polytechnic State University at San Luis Obispo and Prof. Bob Twiggs of Stanford University's Space Systems Development Lab [4-6]. CubeSats are classified according to a standard $1 \mathrm{U}$ unit, defined to be a $10 \times 10 \times 10 \mathrm{~cm}^{3}$ volume with a mass of no more than $1.33 \mathrm{~kg}$ [7]. Most CubeSats limit power consumption to only a few Watts and rarely boast available data rates in excess of $1 \mathrm{Mbps}$. CubeSats have been designed, built, tested and launched by universities at costs ranging between $\$ 50,000$ and $\$ 200,000$ [8], ranging in size from $1 \mathrm{U}$ to $27 \mathrm{U}$. The first CubeSats were launched in 2003 [9], with a total of 471 CubeSats with a size of $1 \mathrm{U}$ or larger having been launched as of August 2016. Just about $99 \%$ of all launches fall within the $1 \mathrm{U}$ to $3 \mathrm{U}$ range. $3 \mathrm{U}$ CubeSats constitute an absolute majority of all launches at about $57 \%$, while their $1 \mathrm{U}$ counterparts make up about $29 \%$ of all launches [1]. To date, the June 2016 launch of the 12U Aoxiang Zhixing (Aoxiang-Sat) satellite developed by Northwestern Polytechnical University in China represents the largest CubeSat class to be successfully launched [1], with a 27U successor still in development. The CubeSat satellite market has grown 205\% from 2016 to 2017, and more than 263 small satellites are expected to be launched in 2018 [10]. That CubeSats have little mass, are small in size and require little power results in low payload costs which allow technology developers to fly their products aboard space missions without exposing themselves to excessive financial risk [4]. As CubeSat technology

This paper was recommended for publication in revised form by Regional Editor Erdal Güven

1 Satellite Programs Directorate, Turksat A.S., Golbasi, Ankara, Turkey

${ }^{2}$ Mechanical Engineering Department, Sakarya University, Esentepe, Sakarya,, Turkey

*E-mail address: bulut44@gmail.com, sozbir@sakarya.edu.tr

Orcid id: 0000-0002-9024-7722, 0000-0003-4633-2521

Manuscript Received 11 February 2019, Accepted 24 April 2019 
continues to play an increasing role in the development and assessment of small and large spacecraft, it is important to consider how the large number of thermal cycles and high heat inputs from solar radiation and Earth's infrared affect such LEO satellites as CubeSats [11].

\section{REVIEW OF LITERATURE}

Although the thermal design, analysis and testing of CubeSat platforms is a widely studied subject with a large corpus of published work [12-23], there persists a lack of coverage of the topic in established literature as it relates to the $3 \mathrm{U}$ class [20]. Moffitt et al. [12] studied thermal modelling to aid in design and analysis of a combat sentinel satellite. Tsai used a general thermal mathematical model featuring a combined conduction-radiation heat transfer equation with environmental heating and cooling captured as boundary conditions [13]. In performing thermal analysis for the United Kingdom universal bus experiment (UKube-1) nanosatellite, Reiss investigated new methodologies using a MATLAB-based software tool to improve accurate in thermal modelling and analysis, and subsequently compared his results with those of the professional software ESATAN-TMS wherein similar temperature distributions reported by both programs [14]. Escobar et al. [15] explored implementing genetic algorithms to automate the design of thermal controls for small satellites. Thanarasi [16] performed thermal analysis for a CubeSat subjected to worst-case scenario hot and cold environmental conditions by means of finite element analysis (FEA) using MSC Software's Nastran and Patran packages. Bulut et al. [17] attempted the thermal modelling and analysis of a CubeSat by using the spreadsheet-based ThermXL tool. Onetto et al. [18] undertook the design and analysis of a CubeSat under LEO thermal conditions. Bulut et al. [19] investigated the panel surface temperatures and overall thermal behavior of a $1 \mathrm{U}$ nanosatellite platform using finite-difference methods. The study took into consideration the effects of orbit altitude, panel configuration and the proportion of solar cells and painted aluminum along the satellite's exterior. Results showed an increase of $12{ }^{\circ} \mathrm{C}$ after applying a black paint coating over $7 \%$ of the satellite structure initially covered with $60 \%$ solar cells and $40 \%$ aluminum sheeting. The assembly, integration and testing of the Delfi-C3 nanosatellite was presented by Brouwer et al. [20] Delfi-C3 was thermally tested on satellite level in a TVAC with shroud temperature ranging between $-110{ }^{\circ} \mathrm{C}$ and $80{ }^{\circ} \mathrm{C}$. Escobar et al. [21] described the evolutionary design of a satellite thermal control system intended for use in CubeSat missions. Corpino et al. [22] explored using finite differences to model the thermal behavior satellites in LEO. The results obtained by using their proposed finitedifference methodology were compared with those from ESATAN-TMS. Diaz-Aguado et al. [23] considered the thermal design of the FASTRAC nanosatellite when exposed to vacuum conditions, and then compared their results with those obtained using FEA. Bauer et al. [24] calculated unsteady temperature distributions for a multi-orbit duration by considering the effects of solar and terrestrial (black-body) radiation, in addition to preliminary analysis of heat generation from internal components. Czernik [25] discussed the thermal design and analysis of Compass-1, a $1 \mathrm{U}$ class CubeSat built for a circular, sun-synchronous LEO. Dinh designed and build a $1 \mathrm{U}$ CubeSat and studied the external orbital radiation heat flux with numerical and analytical approaches [6]. Garzon [11] researched, developed and verified conceptual and analytical models of the thermal controls for the OSIRIS-3U space weather research platform. Time-dependent COMSOL FEA models of OSIRIS-3U were created and simulated for 20 orbital periods. The worst-case hot solutions showed that OSIRIS-3U would reach temperatures above the operating temperature of critical components, most importantly its batteries. Moffitt et al. [26] use SDRC I-DEAS's thermal model generator (TMG) tool in revisiting their thermal model of a combat sentinel satellite. Smith [27] developed a working thermal model of the CubeSat NPS-SCAT. Robust environmental modelling and testing were completed to ensure that NPSSCAT operates successfully when in orbit. Trinh [28] presented environmental testing and orbital decay analysis for a CubeSat called the TechEdSatCubeSat. A thermal vacuum cycling test was conducted at temperatures from -10 to 50 ${ }^{\circ} \mathrm{C}$ and held for 45 minutes with two cycles. Osdol et al. [29] developed a 3U CubeSat nanosatellite platform which was designed to support any payload. Thermal analysis was completed using the SatTherm MATLAB package. Sensitive components as well as the assembled satellite were subjected to vibration, thermal cycling and vacuum testing. Chandrashekar [30] studied thermal analysis and control of the MIST CubeSat. The CubeSat SERPENS was developed by a consortium of Brazilian and international universities. It was built in a $3 \mathrm{U}$ platform $(10 \mathrm{~cm} \mathrm{x} 10 \mathrm{~cm} \mathrm{x}$ $30 \mathrm{~cm}$ ) tested at the Integration and Testing Laboratory at the National Institute of Space Research in São José dos Campos, São Paulo [31]. It was launched to the International Space Station on August 19, 2015 by the Japanese launch 
vehicle H-IIB, with a mission life of about six months. SERPENS was built to be tested within two models: the engineering model (EM) and the flight model (FM) [31]. EM underwent a burn-in test, whereas FM underwent a thermal cycling test (TCT) [31].

The TURKSAT-3USAT program is a recent satellite program which includes in its scope a focus on CubeSat thermal analysis. The TURKSAT-3USAT program is set up in the framework of a university program and serves to further educational, scientific and technological interests in line with this kind of initiatives. The TURKSAT-3USAT program is funded by the TURKSAT, A.S. company. The Space Systems Design and Test Laboratory and Radio Frequency Electronics Laboratory of ITU were contracted under the TURKSAT-3USAT program to provide a CubeSat for use as amateur radio. The Space Systems Design and Test Laboratory of ITU was also contracted to build and calibrate a detailed thermal model to be used during TVAC testing. TURKSAT-3USAT's payload consists of an amateur band VHF/UHF transponder for use in voice communication. The generic, modular ISIS 3-Unit CubeSat platform was chosen to serve as TURKSAT-3USAT's main structure.

This paper address three principal topics. These are (1) general considerations of the thermal design, (2) the thermal analysis performed using ThermXL and ESATAN-TMS and (3) the results obtained from thermal testing in a TVAC.

\section{EXTERNAL THERMAL ENVIRONMENT}

One of the most challenging issues in satellite systems engineering is contending with the thermal environment. The thermal inputs which contribute to the heating of a spacecraft in a LEO are couplings between the environment and heat generation from internal components. The atmospheric conditions encountered in near-Earth space profoundly influence the performance and operational lifetime of spacecraft orbiting in that band of space [6].

In space, heat radiated from the sun, albedo (the reflection of solar radiation of other celestial bodies such as the Earth), and planetary heating from the Earth by means of black-body radiation are the three primary sources of heat for general spacecraft systems in a LEO [32]. Direct solar radiation is the amount of radiation which is emitted by the Sun and strikes any object in space [11]. As direct solar radiation gets absorbed by the planet Earth, a fraction of this flux is reflected out into space, which is known as the Earth's reflected solar energy or albedo [11]. The Earth is considered to be a source of constant temperature. This source results in the planet emitting radiant energy in the infrared (IR) region of the spectrum, which is known as the Earth's infrared radiation [11]. An object's material properties and its orientation with respect to the sun dictate the amount of external heat absorbed directly from solar energy. A generalized energy balance between the satellite and its surrounding in space is shown in Figure 1. The temperature of the satellite at any given point of its orbit is a product of the balance between all absorbed and emitted energy fluxes.

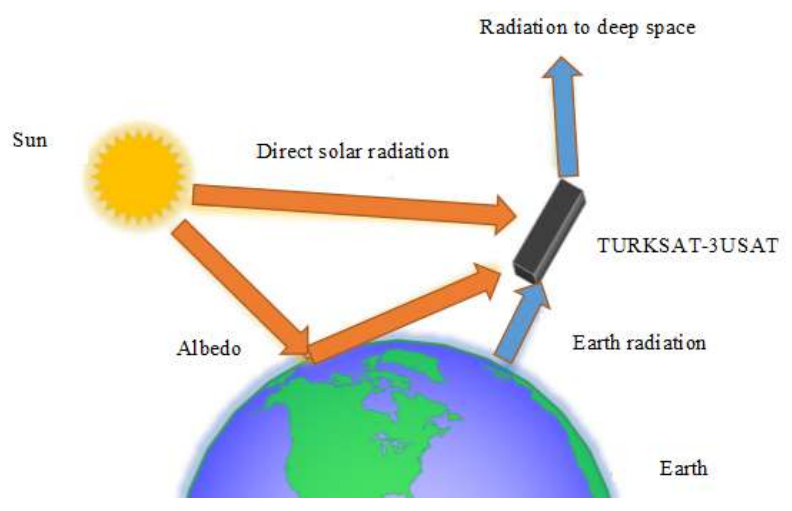

Figure 1. Thermal environments for TURKSAT-3USAT

Table 1 provides approximate values for solar flux, Earth albedo, and Earth IR for the average, hot and cold cases considered in this paper. A more detailed description of each of the primary sources of radiation under consideration in this paper is available in Gilmore's Spacecraft Thermal Control Handbook [33]. The integrated, radiative flux from the sun witnessed in LEO varies slightly throughout the year, from $1414 \mathrm{~W} / \mathrm{m}^{2}$ during the winter 
solstice to $1323 \mathrm{~W} / \mathrm{m}^{2}$ at the summer solstice. This variation is due to different distances between the Earth and sun at certain times during the year [34].

Table 1. Environmental heat sources: hot and cold cases

\begin{tabular}{|l|c|c|}
\hline Parameter & Hot Case & Cold Case \\
\hline Orbital Parameters & $\begin{array}{c}\text { permanently } \\
\text { illuminated }\end{array}$ & $\begin{array}{c}\text { max eclipse } \\
\text { time }\end{array}$ \\
\hline & $\mathrm{W} / \mathrm{m}^{2}$ & $\mathrm{~W} / \mathrm{m}^{2}$ \\
\hline Solar Flux & 1414 & 0 \\
\hline Earth Albedo & 494.9 & 0 \\
\hline Earth IR & 260 & 220 \\
\hline
\end{tabular}

\section{U CUBESAT MODEL: TECHNICAL OVERVIEW}

TURKSAT-3USAT is a 3U CubeSat, meaning that it consists of three stacked cubic units having a total volume of $10 \times 10 \times 34 \mathrm{~cm}^{3}$. The three stacks are referred to as the upper, middle and lower stacks, respectively, and house both the subsystems and the payloads. TURKSAT-3USAT is designed to accommodate the maximum possible redundancy, wherein all subsystems have a back-up with similar architecture. A model of the satellite's build is shown in Figure 2. Where possible, both COTS and in-house system components are employed in the satellite's design. All subsystems composed of COTS goods are listed in Table 2. TURKSAT-3USAT flight model is shown in Figure 3.

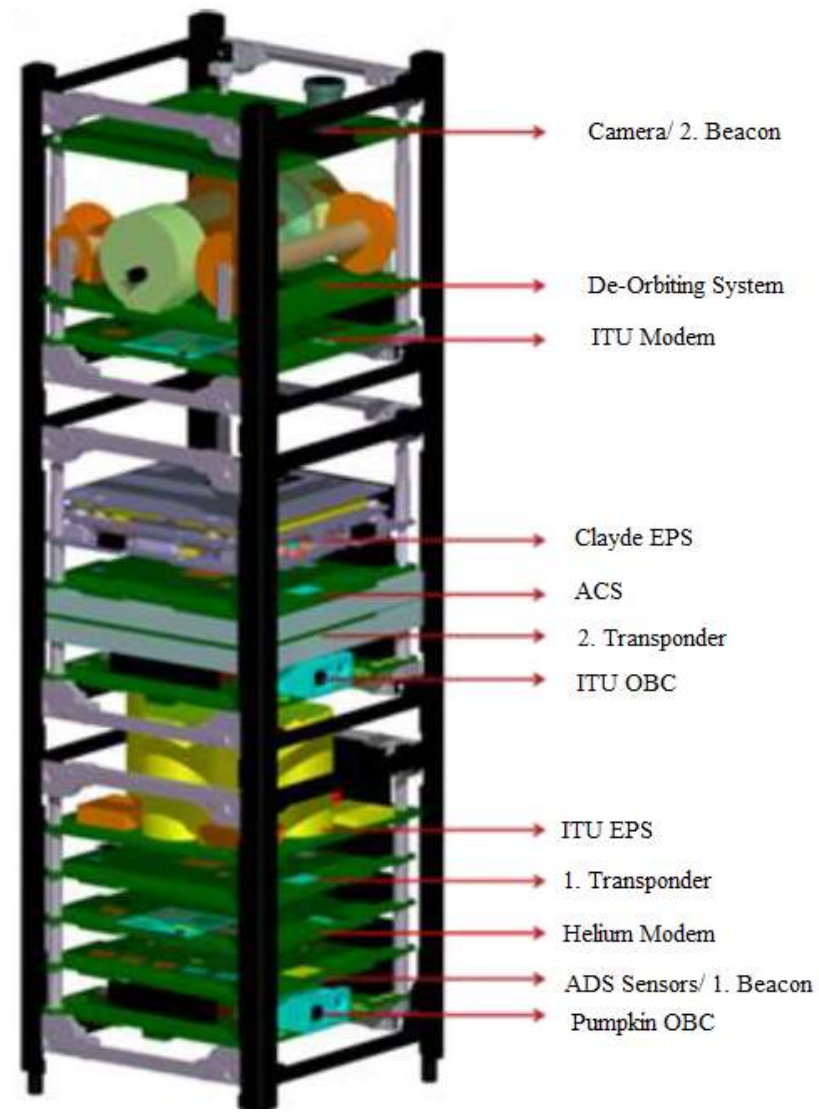

Figure 2. The subsystems of TURKSAT-3USAT 
Table 2. TURKSAT-3USAT components and subsystems

\begin{tabular}{|l|c|c|}
\hline Subsystem & Development & COTS \\
\hline Structure & İTÜ & ISIS3U \\
\hline OBC & İTÜ & Pumpkin \\
\hline ADC & ITTÜ & \\
\hline Modem & İTÜ & Astronautical Dev. \\
\hline Beacon & İTÜ & \\
\hline Transponder & İTÜ & TAMSAT \\
\hline Antenna opening & ITÜ & Clyde Space \\
\hline Battery & İTÜ & Clyde Space \\
\hline EPS & İTÜ & Clyde Space \\
\hline Solar Cells & 1 panel & \\
\hline De Orbiting & İTÜ & \multicolumn{2}{|l}{} \\
\hline
\end{tabular}

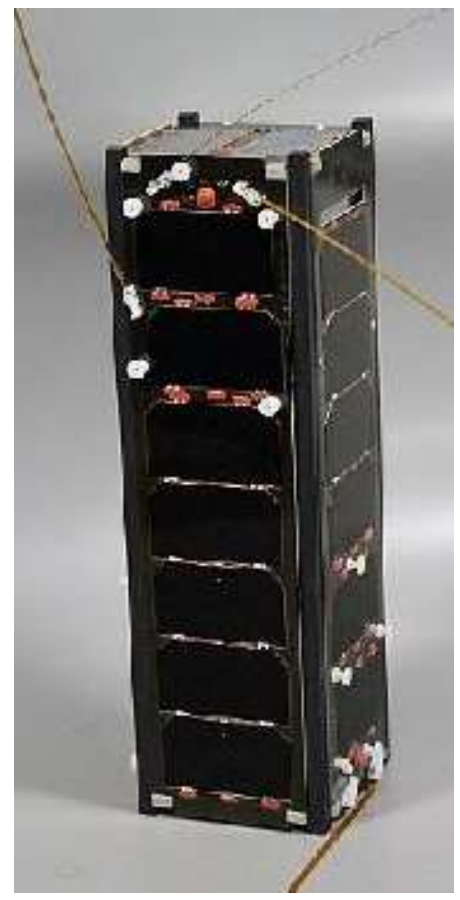

Figure 3. TURKSAT-3USAT flight model

\section{THE THERMAL DESIGN OF THE THERMAL CONTROL SYSTEM}

Given the strict limits on volume, weight and mission costs - all in addition to the harsh environmental conditions in space - the design of a satellite system is necessarily complex [15]. Among the most difficult tasks to achieve is satisfying the required temperature specifications needed to ensure that all components of a satellite are held within their operable temperature ranges [20,35-39]. The thermal design of small spacecraft has more limitations compared to that of larger spacecraft. Although passive thermal control is generally preferred for all spacecraft due to its simplicity and cost, it is almost required in small spacecraft. Thermal design is of paramount concern since even the initial stages of any satellite program on account of its importance to maintaining proper equipment functioning and to minimizing mass and power requirements. TURKSAT-3USAT's temperature control is driven by carefully selected surface properties and insulation. The infrared emissivity and solar absorptivity of areas nearest the solar panels are selected to safeguard system components from temperatures outside of their operating limits [40]. 
TURKSAT-3USAT's thermal requirements are primarily based on the component operating temperature ranges, the internal heat generation from the power dissipated by those same components and the external thermal loads from the external environment. The operating temperature ranges of each of TURKSAT-3USAT's components are summarized in Table 3.

Table 3. Operational temperature range of subsystems

\begin{tabular}{|l|c|}
\hline Subsystem & Operational Temperature Range \\
\hline Main Structure & $-40{ }^{\circ} \mathrm{C}+85{ }^{\circ} \mathrm{C}$ \\
\hline ADCS & $-30{ }^{\circ} \mathrm{C}+85{ }^{\circ} \mathrm{C}$ \\
\hline Batteries & $-5{ }^{\circ} \mathrm{C}+25^{\circ} \mathrm{C}$ \\
\hline Solar Panel & $-40{ }^{\circ} \mathrm{C}+85{ }^{\circ} \mathrm{C}$ \\
\hline EPS & $-40{ }^{\circ} \mathrm{C}+85{ }^{\circ} \mathrm{C}$ \\
\hline CDHS & $-30{ }^{\circ} \mathrm{C}+60{ }^{\circ} \mathrm{C}$ \\
\hline Antenna & $-40{ }^{\circ} \mathrm{C}+85{ }^{\circ} \mathrm{C}$ \\
\hline Transponder & $-40{ }^{\circ} \mathrm{C}+85{ }^{\circ} \mathrm{C}$ \\
\hline OBC & $-40{ }^{\circ} \mathrm{C}+85{ }^{\circ} \mathrm{C}$ \\
\hline De-Orbiting System & $-70{ }^{\circ} \mathrm{C}+70{ }^{\circ} \mathrm{C}$ \\
\hline Camera & $-40{ }^{\circ} \mathrm{C}+85{ }^{\circ} \mathrm{C}$ \\
\hline
\end{tabular}

A passive thermal protection system was decided upon because of its light mass, lack of energy requirements and easy implementation. The passive thermal system consists of a Kapton material layer covering the outer faces of the solar panels, as well as Mylar films which prevent heat loss. In addition to passive thermal system, there are heaters on the Clyde Space EPS to keep the operational temperature of the batteries between $-5{ }^{\circ} \mathrm{C}$ and $25^{\circ} \mathrm{C}$. The material properties of the covered surfaces are displayed in Table 4. Projected area of aluminum and solar cells are 3.96 E-03 $\mathrm{m}^{2}, 6.04 \mathrm{E}-03 \mathrm{~m}^{2}$, respectively.

Table 4. Material properties

\begin{tabular}{|c|c|c|c|c|}
\hline Materials & $\begin{array}{c}\text { Thermal } \\
\text { Conductivity (k) } \\
\end{array}$ & $\operatorname{Absorptivity}(\alpha)$ & Emissivity $(\mathcal{E})$ & $\begin{array}{l}\text { Specific Heat } \\
\text { Capacity }\left(c_{p}\right) \\
\end{array}$ \\
\hline & $\mathrm{W} / \mathrm{m}^{\circ} \mathrm{C}$ & & & $\left(\mathrm{J} / \mathrm{kg}^{\circ} \mathrm{C}\right)$ \\
\hline Aluminum 7075-T73 & 155 & 0.08 & 0.15 & 960 \\
\hline GaAs Solar Cells & 55 & 0.91 & 0.81 & 327 \\
\hline Kapton & 0.12 & 0.87 & 0.81 & 1090 \\
\hline FR-4 & 0.27 & 0.80 & 0.80 & 600 \\
\hline
\end{tabular}

To maximize the power available to the satellite and its components whilst in orbit, much of TURKSAT3USAT's outer surface area is covered with solar cells. Being that solar cells act essentially as flat plate absorbers and cannot be covered by other materials without significantly reducing their performance, the optical properties of the satellite's exterior cannot be altered easily.

The total mass of TURKSAT-3USAT is $3154 \mathrm{~g}$. The mass budget is shown in Table 5. 
Table 5. Mass budget

\begin{tabular}{|l|c|}
\hline Subsys tem & Mass (g) \\
\hline Structure & 620 \\
\hline EPS (controller and batteries) & 779 \\
\hline Mechanism & 82 \\
\hline Solar Panels & 701 \\
\hline Communication & 176 \\
\hline C\&DHS & 169 \\
\hline Cable\& Connectors & 181 \\
\hline Passive stabilization & 220 \\
\hline Transponder & 196 \\
\hline Camera-sensors & 30 \\
\hline Total & $\mathbf{3 1 5 4}$ \\
\hline
\end{tabular}

\section{THERMAL ANALYSIS AND THERMAL ENERGY BALANCE}

Thermal analysis is undertaken in order to guarantee that all spacecraft subsystems and components are kept within their operating temperature limits for all phases of a mission [32]. As such, analysis is concerned with interpreting the results obtained not for predicting temperatures. TURKSAT-3USAT is intended for use in a LEO, meaning that it is expected to sustain a relatively large number of thermal cycles. Thermal analysis of the satellite is carried out using ThermXL and ESATAN-TMS software. ThermXL is an Excel-based spreadsheet thermal analysis tool, and ESATAN-TMS is a computer program which uses a lumped parameter method. TURKSAT-3USAT is the exit its launcher at an altitude of approximately $680 \mathrm{~km}$, where atmospheric pressure and drag are minuscule; thus, the effects of aerodynamic heating and convective heat transfer are neglected.

Thermal control is the application of a thermal energy balance to a satellite so as to confirm that all subsystems and components remain within their operating temperature limits during worst-case hot and cold scenarios. External heating loads from the environment as well as internal heat generation must together be properly balanced against the excess heat which a spacecraft radiates to space. This kind of energy balance analysis is especially useful for determining whether or not a satellite has sufficient radiative area and survival heating power to maintain its temperature within acceptable limits for the worst-case hot and cold scenarios, respectively [4].

The heat balance for each element is based on analyzing the heat flow from all directions both into and out of the element. This method is similar to a control volume approach. The differential equation for the heat balance is given equation (1) [26],

$$
M_{i} C_{p i} \frac{d T_{i}}{d t}=Q_{\text {in }}-Q_{\text {out }}
$$

where $M_{i}$ is mass, $C_{p i}$ is specific heat, $d T_{i} / d t$ is the temperature derivative with respect to time, $Q_{i n}$ is the sum of all heat flows into the element, $Q_{\text {out }}$ is the sum of all heat flows out of the element and the subscript $i$ is used as an index to represent an element number. The equilibrium temperature can be found by $Q_{i n}=Q_{\text {out }}$

The heat balance equation for node $i$ coupled with nodes $j$ through $n$ is shown in equation $(2)[12,41]$

$$
\begin{gathered}
\left(M_{i} C_{p}\right)_{i} \frac{d T_{i}}{d t}=Q_{i}^{d}+\left(Q_{\text {Sun }}+Q_{\text {albedo }}+Q_{\text {EarthIR }}\right)_{i} \\
-\sum_{j} \Im_{i j} A_{i}^{r}\left(\sigma T_{i}^{4}-\sigma T_{j r}^{4}\right)-\sum_{j} K_{i j}\left(T_{i}-T_{j k}\right)
\end{gathered}
$$

where $\sigma$ is the Stefan-Boltzmann constant, $A$ is area, conduction couplings is presented as $K_{i j}$ and $\mathfrak{I}_{i j}$ is the gray-body view factor from element $\mathrm{i}$ to element j. $T$ is temperature, $Q_{d}^{i}$ is internal dissipation, $Q_{S u n}$ is solar radiation, 


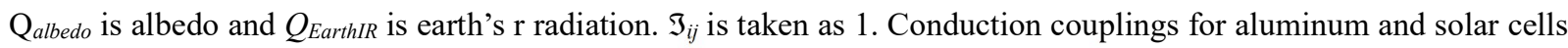
are $2.33 \mathrm{E}-01 \mathrm{~W} /{ }^{\circ} \mathrm{C}$ and $2.21 \mathrm{E}+03 \mathrm{~W} /{ }^{\circ} \mathrm{C}$.

The incident solar radiation can be determined from equation (3),

$$
Q_{\text {Sun }}=A_{p}, \alpha_{s}, S
$$

where $A_{p}$ is the projected area, $\alpha_{s}$ is the absorptance of external surfaces, and $S$ is the solar constant (Solar flux). Albedo is given as follows in equation (4),

$$
Q_{\text {albedo }}=\left(A_{p}, F_{\text {sat-earth }}\right) \cdot \alpha_{s}, f_{a} \cdot S \cdot \cos \theta
$$

where, $f_{a}$ is the albedo factor and $\theta$ is the angle representing satellite position with respect to the zenith. It is important to note that the albedo factor varies as a result of differences between Earth's many surface types. Albedo factor range from zero (no reflection) to one (100\% reflection).

Earth'S radition is shown in equation (5),

$$
Q_{\text {EarthIR }}=\left(A_{p} \cdot F_{\text {sat-earth }}\right) \cdot \varepsilon \cdot G
$$

where $\varepsilon$ is the emittance of external surfaces, and $G$ is the Earth's radiation flux and $F_{\text {satearth }}$ is the view factor from the satellite to the Earth.

A thermal model of the satellite implementing the above isothermal node concepts was developed using ESATAN-TMS. The external faces of TURKSAT-3USAT are laid out in Figure 4. As a 3U-class CubeSat, TURKSAT3USAT is the combination of three $1 \mathrm{U}$ cubes in the same structure. First cube has five faces (four side faces and one top face), the second cube has four side faces and the third cube has five faces (four side faces and one bottom face). All faces are covered with solar cells. The number of nodes in the model is 30 by using ThermXL. Radiation between internal equipments neglected. The analysis cases are defined by analyzing external thermal environment and the operational conditions. ESATAN-TMS used for the calculation of the external fluxes.

\section{Hot and Cold Cases for TURKSAT-3USAT Thermal Analysis}

The two operational scenarios selected for analysis are the hot and cold worst-case scenarios.

The hottest-case scenario is expected to occur when the satellite payload's most demanding operational power mode is in effect at the same time that the satellite's largest surface is oriented perpendicularly to the sun's incident radiation. The hottest temperature which the satellite should encounter in orbit is at full sunlight phases, where solar radiation, albedo and Earth's infrared radiation (IR) are all present. The latter two thermal loads (albedo and Earth's IR) should also increase as the distance between the satellite's orbit and the Earth's decreases. As such, the hottestcase scenario for TURKSAT-3USAT corresponds to an altitude of $680 \mathrm{~km}$, with the anticipated maximum heat fluxes given in Table 1.

The coldest-case scenario is most likely to occur when the payload's operational power mode is at its lowest and while only the satellite's smallest face is pointed toward the sun. In this scenario, there should be no direct solar radiation nor albedo but only Earth's IR, which decreases as the satellite moves farther away from the Earth. It is important to consider that, without any exposure to direct solar radiation or albedo, the satellite's solar panel array is incapable of generating electric power can be generated by the solar cells [25]. Thus, the Earth's IR is only the external thermal load experienced during the coldest-case scenario. 


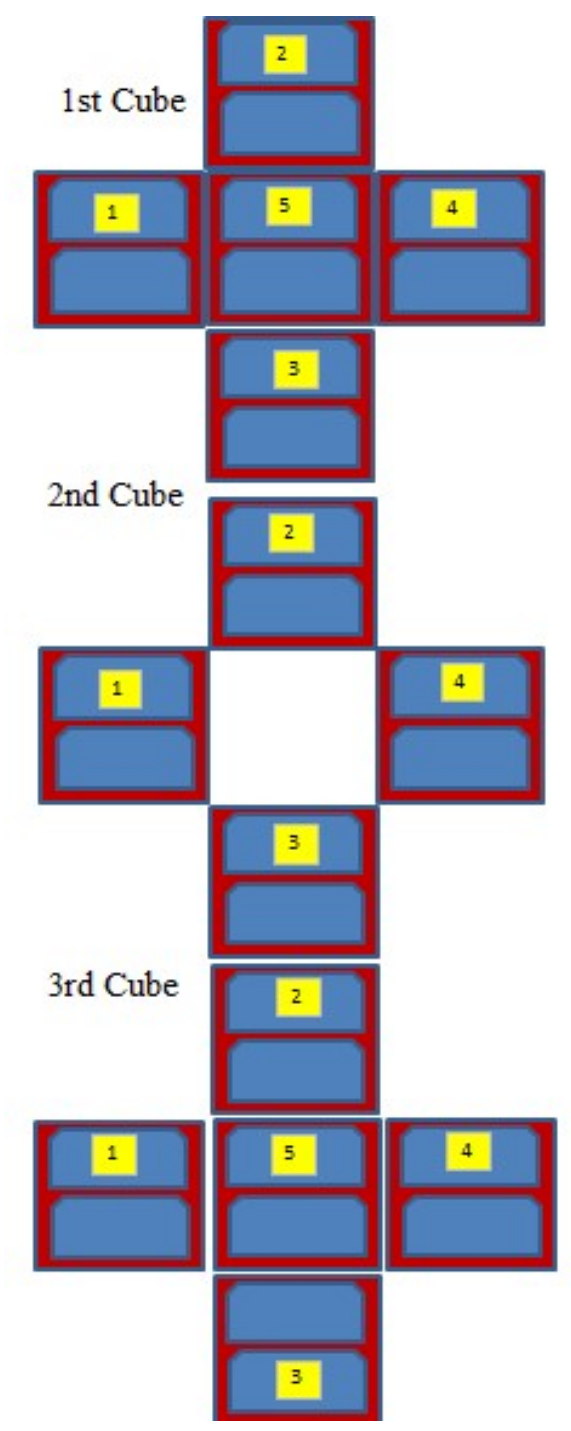

Figure 4. Faces of TURKSAT-3USAT

\section{THERMAL TESTING}

Unlike most conventional satellites which tend to be large, heavy and fairly complex CubeSats are well-suited for total system TVAC testing, owing to their small size, light weight and simplicity of design.

Thermal testing is of great importance in validating and qualifying the ability of any spacecraft to withstand the harsh environmental conditions experienced while in space, namely drastic temperature variations and nearvacuum pressures. In order to achieve those types of conditions for experiments conducted in a laboratory setting, the use of a TVAC is warranted.

Two different tests are conducted using a TVAC: (1) thermal cycling and (2) thermal bake-out. During the former, the CubeSat is subjected to a number of cycles alternating between minimum and maximum temperatures and is held for one hour at each temperature extreme. The CubeSat must remain fully functional and operational while its subsystems and instrumentation are tested throughout the course of four TVAC cycles.

Thermal bake-outs are an important part of hardware testing in order to remove excess contaminants that may be harmful to the launch vehicle or primary payload [42]. This is accomplished via an outgassing of all subsystems, for which no more than $1 \%$ of the CubeSat's overall mass should be lost. During this procedure, the satellite is kept in a non-operational state. 
At the integrated vehicle level, CubeSat missions are typically only required to conduct a thermal bake-out. Complete multi-cycle TVAC testing can, however, be carried out on the qualification vehicle (vehicle powered) to mitigate the risk of unforeseen thermal issues [43]. The primary aim of TURKSAT-3USAT's thermal cycling test is to provide a thermal environment to the components identical to that of space.

\section{Thermal Test Facilities and Thermal Testing Test-up}

TURKSAT-3USAT's TVAC testing made possible the observation and measurement of the satellite's thermal equilibrium state, as well as a performance evaluation of components in conditions approximating those of LEO. The TVAC used to perform thermal testing is shown in Figure 5. It is located at the Space Systems Design and Test Laboratory of ITU. The TVAC's useful volume is $350 \mathrm{~L}$, and it is capable of supplying up to $10^{-6}$ mbar of pressure and reaching temperature extremes of $-60^{\circ} \mathrm{C}$ and $+125^{\circ} \mathrm{C}$ with ramp rates of at most $1{ }^{\circ} \mathrm{C}$ per minute. ANGELTONI's WINKRATOS software serves as the TVAC's operating system. Prior to testing, five thermal sensors (PT 100) were affixed to the device under test (DUT) at the following locations: (1) the middle of the top surface, (2) the edge of the top surface, (3) the edge of a side surface, (4) the middle of the bottom surface and (5) the edge of the bottom surface.

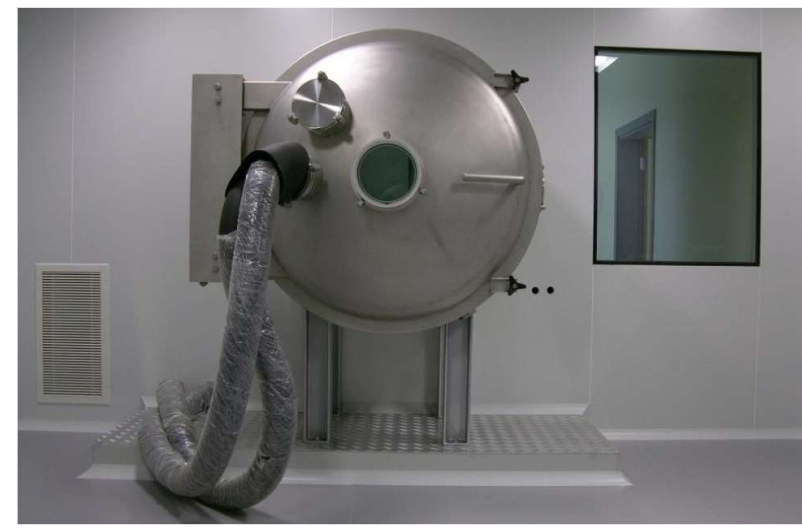

Figure 5. ITU's thermal vacuum chamber

Figure 6 shows TURKSAT-3USAT in a TVAC [44]. Twenty-five thermocouples were installed in order to measure the components' temperatures during testing. Qualification tests ran for eight cycles with at least $10{ }^{\circ} \mathrm{C}$ of design margin at temperature extremes. Acceptance tests were done at a minimum four cycles with at least $5{ }^{\circ} \mathrm{C}$ of design margin at temperature extremes. Full functional checkouts were conducted both before and after each test. The tests were conducted in such a way so as to ensure low levels of outgassing at a minimum vacuum pressure of $5 \times 10^{-4}$ mbar. Pressure in the TVAC was $10^{-5}$ mbar, while temperature was between $-40{ }^{\circ} \mathrm{C}$ and $+80{ }^{\circ} \mathrm{C}$.

TURKSAT-3USAT was subjected to a thermal vacuum bake-out test for 24 hours at $50{ }^{\circ} \mathrm{C}$ before integration with the P-POD to ensure the proper outgassing of components. As mentioned before, the satellite should not experience a total mass loss exceeding $1 \%$ as a result of outgassing, nor should it be operational during the procedure [45].

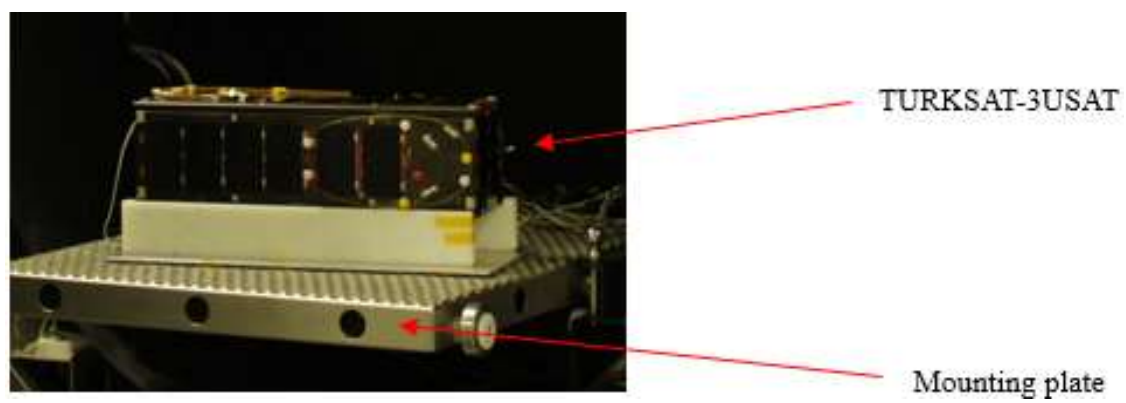

Figure 6. TURKSAT-3USAT in the TVAC [44] 


\section{THERMAL ANALYTICAL RESULTS VS THERMAL TEST RESULTS}

\section{Thermal Analysis Results}

The thermal control subsystem is responsible for maintaining the satellite's temperature within a predefined range. Thermal analysis tools ThermXL and ESATAN-TMS were used to carry out a transient thermal analysis, the results of which for both the hottest-case and coldest-case scenarios are listed in Table 6. It can be seen from those data that the maximum temperatures vary between $20.84^{\circ} \mathrm{C}$ and $62.42^{\circ} \mathrm{C}$. The transponder has the highest temperature of $62.42^{\circ} \mathrm{C}$, whereas the camera and beacon have the lowest temperature of $20.84^{\circ} \mathrm{C}$. Thus, there is a $41.58^{\circ} \mathrm{C}$ difference between the lowest and highest temperatures at the maximum temperature level.

Minimum temperature values vary between $-21.74{ }^{\circ} \mathrm{C}$ and $-10.29^{\circ} \mathrm{C}$. The camera and beacon have the lowest temperature of $-21.74{ }^{\circ} \mathrm{C}$, whilst the Pumpkin $\mathrm{OBC}$ has the highest temperature of $-10.29^{\circ} \mathrm{C}$. As such, there is an 11.45 ${ }^{\circ} \mathrm{C}$ difference between the lowest and highest temperatures at the minimum temperature level. Figure 7 shows temperature results obtained by ESATAN-TMS $[44,46]$. The temperature results show average values in orbit.

Table 6. Thermal analysis results

\begin{tabular}{|l|l|l|}
\hline Components & $\begin{array}{l}\text { Max } \\
\left({ }^{\circ} \mathbf{C}\right)\end{array}$ & $\begin{array}{l}\text { Min } \\
\left({ }^{(} \mathbf{C}\right)\end{array}$ \\
\hline Camera\&Beacon & 20.84 & -21.74 \\
\hline De-Orbiting & 26.68 & -21.34 \\
\hline ITU Modem & 35.39 & -20.79 \\
\hline Batteries & 42.56 & -20.31 \\
\hline Clyde EPS & 49.74 & -19.83 \\
\hline Transponder 2 & 59.61 & -19.17 \\
\hline ACS & 43.54 & -18.50 \\
\hline ITU OBC & 38.87 & -17.51 \\
\hline ITU EPS & 52.83 & -15.74 \\
\hline Transponder 1 & 62.42 & -14.64 \\
\hline Helium Modem & 46.70 & -13.68 \\
\hline Sensors & 37.85 & -12.42 \\
\hline Pumpkin OBC & 33.38 & -10.29 \\
\hline
\end{tabular}

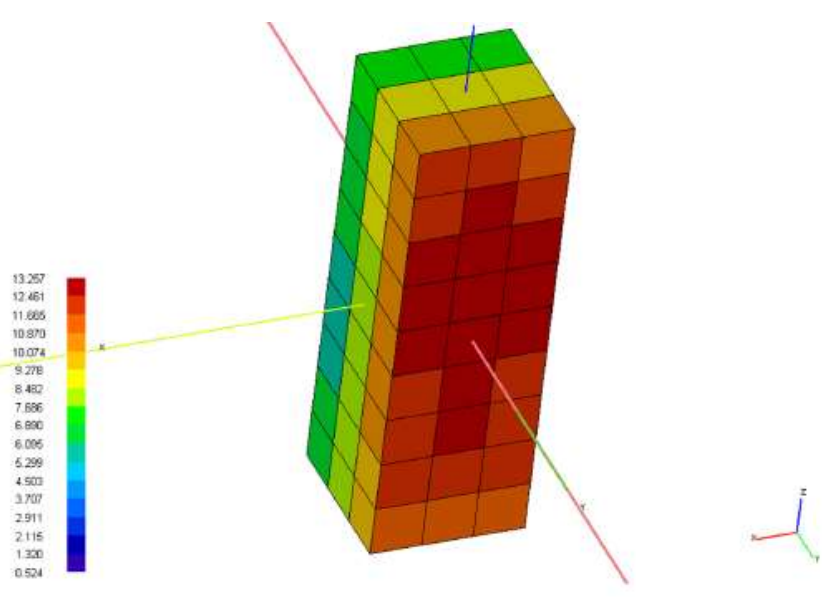

Figure 7. TURKSAT-3USAT average temperature results in orbit $[44,46]$ 


\section{Thermal Test Results}

Thermal cycling testing was completed under vacuum conditions. The satellite and its components were subjected to four hot and cold cycles between $80{ }^{\circ} \mathrm{C}$ and $-40^{\circ} \mathrm{C}$. Thermal cycling test results for some components are shown in Figures 8 and 9. Figure 8 shows the camera card's thermal cycling test results, and Figure 9 shows the Pumpkin OBC's results. The functional test was performed during the first and last hot and cold cycles to demonstrate that all components operate as intended. Finally, the flight model of TURKSAT-3USAT was baked-out in a vacuum at a temperature of $50{ }^{\circ} \mathrm{C}$ for 24 hours. Temperatures were not monitored during the bake-out. After the bake-out was finished, the satellite performance tests reintroduced power to the electronic components.

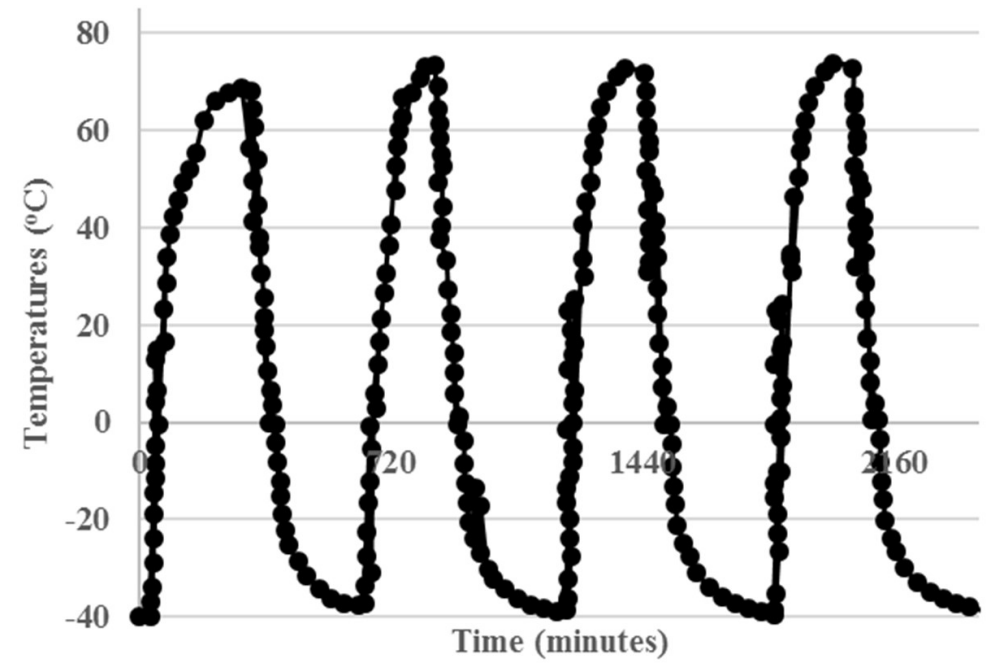

Figure 8. Camera card thermal cycling test results [44]

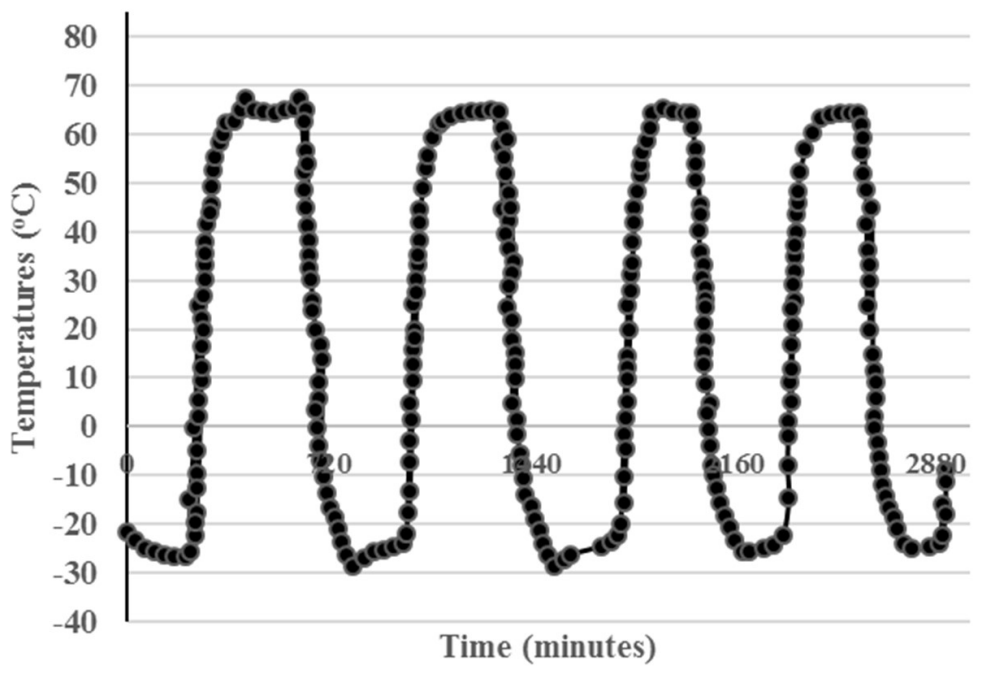

Figure 9. OBC thermal cycling test results [44]

\section{CONCLUSIONS}

A detailed thermal analysis was conducted for the TURKSAT-3USAT CubeSat mission to predict temperatures of the components, which were then compared to test results. The analysis took into consideration the effects of conduction throughout the simple $3 \mathrm{U}$ cube structure as well as thermal loading from environmental radiation to determine maximum and minimum temperature limits for the worst-case hot and cold scenarios. In the worst-case cold scenario, Camera \& Beacon reaches the coldest temperature as $-21.74{ }^{\circ} \mathrm{C}$. In the worst-case hot scenario, 
Transponder 1 reaches the hottest temperature as $62.42^{\circ} \mathrm{C}$. The thermal analysis results show that all of the subsystems except for the batteries were within their respective operational temperature ranges, and thusly that the heaters onboard the Clyde Space EPS will be necessary to provide the operational temperature of the batteries during eclipse periods. Despite that there are many uncertainties in the analysis, there are no significant thermal issues which should threaten minimum mission success.

The CubeSat is the perfect platform to demonstrate new technologies. Therefore, future work can be done by adding radiation contribution between internal equipments. Finally, this study could be of great help and utility to other studies concerning the thermal control of CubeSat systems.

\section{NOMENCLATURE}

$\begin{array}{ll}f_{a} & \text { Albedo factor } \\ t & \text { Time, } \mathrm{s} \\ A_{p} & \text { Projected area, } \mathrm{m}^{2} \\ C_{p i} & \text { The specific heat, } \mathrm{J} / \mathrm{kg} \mathrm{K} \\ d T / d t & \text { Temperature derivative with respect to time } \\ F_{\text {sat-earth }} & \text { View factor from the satellite to the Earth } \\ G & \text { Earth radiation flux, } \mathrm{W} / \mathrm{m}^{2} \\ K_{i j} & \text { Conduction couplings, } \mathrm{W} / \mathrm{K} \\ M & \text { The mass of the node, } \mathrm{kg} \\ Q & \text { Heat rate or heat input, W } \\ Q_{\text {albedo }} & \text { Albedo radiation, W } \\ Q_{\text {EarthlR }} & \text { Earth IR radiation, } \mathrm{W} \\ Q_{i d} & \text { Internal dissipation, } \mathrm{W} \\ Q_{i n} & \text { Internal heat input, } \mathrm{W} \\ Q_{\text {out }} & \text { Outer heat input, } \mathrm{W} \\ Q_{s u n} & \text { Solar radiation, } \mathrm{W} \\ S & \text { Solar constant, } \mathrm{W} / \mathrm{m}^{2} \\ T & \text { Temperature, } \mathrm{K} \text { or }{ }^{\circ} \mathrm{C} \\ T_{i} & \text { Temperature location; node; inner, } \mathrm{K} \text { or }{ }^{\circ} \mathrm{C} \\ T_{j r} & \text { Temperature from node, body, or surface } \mathrm{j} \text { to node, body, or surface } \mathrm{r}, \mathrm{K} \text { or }{ }^{\circ} \mathrm{C} \\ T_{j k} & \text { Temperature from node, body, or surface } \mathrm{j} \text { to node, body, or surface } \mathrm{k}, \mathrm{K} \text { or }{ }^{\circ} \mathrm{C}\end{array}$

Greek symbols

$\alpha_{s}$

The absorptance of external surfaces

$\varepsilon$

The emittance of external surfaces

$\mathfrak{J}_{i j}$

The gray-body view factor from element $i$ to element $j$

$\theta$

The angle of the satellite position with respect to the zenith

\section{ACKNOWLEDGEMENT}

The authors thank to Alexander Borghetti Ferreira for revising the whole manuscript.

\section{FUNDING}

The project is fully supported by TURKSAT, A.S. in Ankara, Turkey.

\section{REFERENCES}

[1] Poghosyan A, Golkar A. CubeSat evolution: Analyzing cubesat capabilities for conducting science missions, Prog. in Aerospace Sciences 2017; 88: 59-83. https://doi.org/10.1016/j.paerosci.2016.11.002

[2] Puig-Suari J, Turner C, Twiggs R. Cubesat: the development and launch support infrastructure for eighteen different satellite customers on one launch. 15th Annual AIAA/USU Conference on Small Satellites, Logan, Utah, 2001.

[3] Cerveno A, Zandbergen B, Guerrieri DC, De Athayde Costa e Silva M, Krusharev I, Van Zeijl H. Green microresistojet research at Delft University of Technology: New options for cubesat propulsion, CESA Space J 2017; 9:111-25.

[4] Willams AD, Palo SA, Korpela SA. Issues and implications of the thermal control systems on the 'six day 
spacecraft'. 4th Responsive Space Conference, Los Angeles, California, USA, 2006.

[5] Toorian A, Blundell E, Puig Suari J, Twiggs R. Cubesats as responsive satellites. 3rd Responsive Space Conference 2005, Los Angeles, CA, 2005.

[6] Dinh D. Thermal modeling of nanosat. Thesis, San Jose State University, California, USA, 2012.

[7] CubeSat Design Specification, revision 13, http://www.cubesat.org/resources/;2018 [Accessed 10 July 2018].

[8] Selva D, Krejci D. A Survey and assessment of the capabilities of cubesats for Earth observation. Acta Astronautica 2009; 70: 50-68. https://doi.org/10.1016/j.actaastro.2011.12.014

[9] Swartwout M. The first one hundred cubesats: A statical look. Journal of Small Satellites 2013; 2 (2): 213-33.

[10] SpaceWorks Enterprises Inc. Nano/Microsatellite Market Forecast. 8th Edition, Tech. report, 03 February 2018.

[11] Garzon M. Development and analysis of the thermal design for the OSIRIS-3U CubeSat. Thesis, The Pennsylvania State University, Pennsylvania, USA, 2012.

[12] Moffitt BA, Batty JC. Predictive thermal analysis of the combat sentinel satellite. 16th AIAA/USU Conference on Small Satellites, Logan, Utah, USA, 2002.

[13] Tsai JR. Overview of satellite thermal analytical model. J of Spacecraft and Rockets 2004; 41 (1): 120-5.

[14] Reiss P. New methodologies for the thermal modelling of cubesats. 26th Annual AIAA/USU Conference on Small Satellites, Logan, Utah, USA, 2012.

[15] Escobar E, Diaz M, Zagal JC. Design automation for satellite passive thermal control, the 4S Symposium, Portoroz, Slovenia, 2012.

[16] Thanarasi K. Thermal analysis of cubesat in worse case hot and cold environment using FEA method. Applied Mechanics and Materials 2012; 225: 497-502. https://doi.org/10.4028/www.scientific.net/AMM.225.497

[17] Bulut M, Kahriman A, Sozbir N. Design and analysis for the thermal control system of nanosatellite. ASME 2010 International Mechanical Congress and Exposition, Vancouver, British Columbia, Canada, 2010.

[18] Onetto R, Paas H, Perez H. Cube satellite design final report. EML design project. Florida International University, Florida, USA, 2010.

[19] Bulut M, Sozbir N. Analytical investigation of a nanosatellite panel surface temperatures for different altitudes and panel combinations, Appl Therm Eng 2015; 75: 1076-83. https://doi.org/10.1016/j.applthermaleng.2014.10.059.

[20] Brouwer GF, Ubbels WJ, Vaartjes AA, Te Hennepe F. Assembly, integration, and testing of the Delfi-C3 nanosatellite, Space systems symposium Lessons learned in space systems. 59th International Astronautical Congress, Glasgow, 2008.

[21] Escobar E, Diaz M, Zagal JC. Evolutionary design of a satellite thermal control system: Real experiments for a Cubesat mission. Appl Therm Eng 2016; 105: 490-500. https://doi.org/10.1016/j.applthermaleng.2016.03.024.

[22] Corpino S, Caldera M, Masoero M, Nichele F, Viola N. Thermal design and analysis of a nanosatellite in low earth orbit. Acta Astronaut 2015; 115: 247-261. https://doi.org/10.1016/j.actaastro.2015.05.012

[23] Diaz-Aguado MF, Greenbaum J, Fowler WT, Glenn Lightsey E. Small satellite thermal design, test, and analysis. Proc. SPIE 6221, Modeling, Simulation, and Verification of Space-based Systems III, 2006.

[24] Bauer J, Carter M, Kelley K, Mello E, Neu S., Orphanos A, Shaffer T, Withrow A. Mechanical, power, and thermal subsystem design for a cubesat mission. Worcester Polytechnic Institute, Project: JB3-CBS2, Worchester Polytechnic Institute, Worcester, Massachusetts, 2012

[25] Czernik S. Design of the thermal control system for compass-1. University of Applied Sciences Aachen, Germany, 2004.

[26] Moffitt BA. Predictive thermal analysis of the combat sentinel satellite test article. Thesis, Utah State University, Logan, Utah, USA, 2003.

[27] Smith KD. Environmental testing and thermal analysis of the NPS solar cell array tester (NPS-SCAT) cubesat. Thesis, Naval Postgraduate School, Monterey, California, USA, 2011.

[28] Trinh GT. Environmental testing and orbital decay analysis for a cubesat. Thesis, San Jose State University, San Jose, California, USA, 2013.

[29] Osdol TCV, Dorsey C, Hedlund J, Hoye T, Jacobs O, Klarreich-Giglio K, Martin E, Ruiz M, Schlesselmann M, Singh Z. Design, fabrication, and analysis of a $3 \mathrm{U}$ cubesat platform, Bachelor of Science Thesis, Santa Clara University, Santa Clara, California, USA, 2013.

[30] Chandrashekar S. Thermal analysis and control of MIST cubesat. Thesis, KTH Royal Institute of Technology, Stockholm, Sweden, 2017.

[31] Fernandes GF, Santos MB, Silva VD, Almeida JS, Nogueira PRM. Thermal tests for Cubesat in Brazil: lessons learned and the challenges for the future. 67th International Astronautical Congress (IAC), Guadalajara, 
Mexico, 2016.

[32] Blom E, Narverud E, Birkeland R. Technical satellite specification. Technical report, 2006.

[33] Gilmore DG. Spacecraft Thermal Control Handbook Volume I: Fundamental Technologies. 2nd ed., El Segundo, CA: The Aerospace Press; 2002.

[34] Spremo S, Bregman J, Dallara C, Ghassemieh S, Hanratty J. Low cost rapid response space spacecraft (LCRRS), A research project in low cost spacecraft design and fabrication in a rapid prototyping environment. 22nd Annual AIAA/USU Conference on Small Satellites, Logan, Utah, 2008.

[35] Bulut M, Gulgonul S, Sozbir N. Thermal control design of TUSAT. 6th International Energy Conversion Engineering Conference, AIAA, Cleveland, Ohio, USA, 2008.

[36] Sozbir N, Bulut M. Thermal control of CM and SM panels for Turkish satellite. SAE 39th International Conference on Environmental Systems, Savannah, Georgia, USA, 2009

[37] Bulut M. Thermal simulation software based on excel for spacecraft applications. Selcuk Univ. J. Eng. Sci. Techn. 2018; 6 (4): 592-600. https://doi.org/10.15317/Scitech.2018.154

[38] Bulut M, Sozbir N. Thermal design of a geostationary orbit communications satellite. Electronics World 2016; 122 (1964): 28-32.

[39] Bulut M, Sozbir N. Heat rejection capability for geostationary satellites. 9. Ankara International Aerospace Conference, Ankara, Turkey, 2017.

[40] Pisacane LV. Fundamentals of Space Systems. 2nd ed., New York, USA: Oxford University Press, 2005.

[41] Karam RD. Satellite Thermal Control for Systems Engineers. Vol.181, AIAA, Reston, VA, 1998.

[42] Bratcher JR. Testing program for KYSAT-1. Thesis, University of Kentucky, USA, 2010.

[43] Bowen J, Villa M, Williams A. Cubesat based rendezvous, proximity operations, and docking in the CPOD mission. 29th Annual AIAA/USU Conference on Small Satellites, Logan, UT, USA, 2015.

[44] Bulut, M. Thermal design, analysis, and testing of the first Turkish $3 \mathrm{U}$ communication CubeSat in low earth orbit. J Therm Anal Calorim 2021. https://doi.org/10.1007/s10973-021-10566-Z

[45] Ampatzoglou A, Kostopoulos V. Design, analysis, optimization, manufacturing, and testing of a 2U cubesat, Hindawi Int J of Aerospace Engineering, 2018, Article ID 9724263 (2018) 15 pages. https://doi.org/10.1155/2018/9724263

[46] Süer M. TURKSAT 3USAT Isıl tasarım raporu, ITU, İstanbul, Turkey, 2011. 